AperTO - Archivio Istituzionale Open Access dell'Università di Torino

A Fast and General Route to Ketones from Amides and Organolithium Compounds under Aerobic Conditions: Synthetic and Mechanistic Aspects

This is a pre print version of the following article:

Original Citation:

Availability:

This version is available http://hdl.handle.net/2318/1788723

since 2021-05-12T12:26:20Z

Published version:

DOI:10.1002/chem.202004840

Terms of use:

Open Access

Anyone can freely access the full text of works made available as "Open Access". Works made available under a Creative Commons license can be used according to the terms and conditions of said license. Use of all other works requires consent of the right holder (author or publisher) if not exempted from copyright protection by the applicable law. 


\title{
A Fast and General Route to Ketones from Amides and Organolithium Compounds under Aerobic Conditions: Synthetic and Mechanistic Aspects
}

\author{
Simone Ghinato, ${ }^{[\mathrm{a}]}$ Davide Territo, ${ }^{[\mathrm{a}]}$ Andrea Maranzana, ${ }^{[\mathrm{a}]}$ Vito Capriati, ${ }^{[\mathrm{b}] *}$ Marco Blangetti ${ }^{[\mathrm{a}] *}$ and \\ Cristina Prandi ${ }^{[a] *}$
}

[a] Dipartimento di Chimica, Università di Torino, via P. Giuria 7, l-10125 Torino (Italy)

E-mail: cristina.prandi@unito.it; marco.blangetti@unito.it

[b] Dipartimento di Farmacia-Scienze del Farmaco, Università di Bari “A. Moro”, Consorzio C.I.N.M.P.I.S., Via E. Orabona 4, I-70125 Bari (Italy)

E-mail: vito.capriati@uniba.it

Supporting information for this article is given via a link at the end of the document. ((Please delete this text if not appropriate))

\begin{abstract}
We report that the nucleophilic acyl substitution reaction of aliphatic and (hetero)aromatic amides by organolithium reagents proceeds quickly $(20 \mathrm{~s}$ reaction time $)$, efficiently, and chemoselectively with a broad substrate scope in the environmentally responsible cyclopentyl methyl ether, at ambient temperature and under air, to provide ketones in up to $93 \%$ yield with an effective suppression of the notorious over-addition reaction. Detailed DFT calculations and NMR investigations support the experimental results. The described methodology was proven to be amenable to scale-up and recyclability protocols. Contrasting classical procedures carried out under inert atmospheres, this work lays the foundation for a profound paradigm shift of the reactivity of carboxylic acid amides with organolithiums, with ketones being straightforwardly obtained by simply combining the reagents under aerobic conditions and with no need of using previously modified or pre-activated amides, as recommended.
\end{abstract}

\section{Introduction}

Ketones are a fundamental class of compounds in organic chemistry, ${ }^{[1]}$ being their reactivity at the crossroad of several cornerstone transformations such as nucleophilic addition reduction and oxidation processes for the obtainment of valuable derivatives. ${ }^{[2]}$ That is the reason why many researchers focus on the investigation of their synthesis. ${ }^{[3]}$ In this context, the chemoselective assembly of ketones by $\mathrm{C}-\mathrm{C}$ bond formation constitutes a well-known intriguing challenge in synthesis. ${ }^{[4]}$ Among the successful strategies the direct conversion of carboxylic acids, ${ }^{[3 e, 5]}$ and sodium methyl carbonates ${ }^{[3]}$ into ketones with organometallic reagents have been reported. However, the direct 1,2-nucleophilic addition of hard organometallic reagents onto carboxylic acid derivatives suffers from a number of limitations depending mostly on the stability of the tetrahedral intermediate, including over-additions and reduction side-reactions. ${ }^{[6]}$ Within this framework, amides exemplify an excellent starting material for the synthesis of ketones due to their large occurrence in nature and easy accessibility. ${ }^{[7]}$ Amides, however, are known to be very unreactive as electrophiles when compared to other carboxylic acids derivatives. ${ }^{[8]}$ The strategies developed over the years to overcome their inner inertness towards nucleophiles can be clustered into three main approaches. One approach relates to the chemical modification of the amide functional group via stable tetrahedral intermediates. ${ }^{[9]}$ In this context, the use of $\mathrm{N}, \mathrm{O}$ dimethylhydroxyamides, better known as Weinreb amides, represents nowadays a versatile tool for the chemoselective synthesis of ketones whose effectiveness relies on the chelation of the metal into the tetrahedral intermediate to form a fivemembered chelate cycle, which hampers its collapse until the reaction quench step (Figure 1a). ${ }^{[10]}$ Stable twisted amides have also been successfully employed by Szostak and co-workers as effective acylating reagents to promote the chemoselective 1,2addition reaction of highly polarised $s$-block organometallic reagents by exploiting pyramidalization as a reactive controlling feature (Figure 1b).$^{[9 c, 11]}$ Reaction of Grignard reagents with $N$ Boc protected amides under kinetic control[8b] and the transformation of amides using gem-diborylalkanes as pronucleophiles are other viable alternatives in using modified amides.$^{[\mathrm{bb}]} \mathrm{A}$ second approach includes the chemical activation of the amide functional group via highly electrophilic intermediates (Figure 1c), $\left.{ }^{[6 a}, 12\right]$ whereas a third synthetic route makes use of transition metal-catalysed $\mathrm{C}-\mathrm{N}$ activation reactions of activated amides delivering a metal acylating agent (Figure 1d). ${ }^{[13]}$ Of note, Feringa and co-workers have also reported the successful synthesis of arylaminoketones via a tandem 1,2-nucleophilic addition of organolithium reagents to benzamide derivatives, followed by a Buchwald-Hartwig amination reaction in THF, which is promoted by the in situ released lithium amide. ${ }^{[14]}$

We have recently thoroughly investigated the reactivity of benzamides with organolithium reagents ${ }^{[15]}$ and shown that either directed ortho-metalation (DoM) or nucleophilic acyl substitution $\left(\mathrm{S}_{N} \mathrm{Ac}\right)$ reactions ${ }^{[15 b]}$ can smoothly and chemoselectively be carried out from the same aromatic, sterically hindered tertiary carboxylic acid amide in the so-called Deep Eutectic Solvents (DESs) as environmentally friendly reaction media ${ }^{[16]}$ in combination with cyclopentyl methyl ether (CPME) ${ }^{[17]}$ working under air, at room temperature $\left(25^{\circ} \mathrm{C}, \mathrm{RT}\right)$ or $0{ }^{\circ} \mathrm{C}$ (Fig. 1e). The chemoselectivity of the process was found to be strongly dependent on the nature of the organolithium reagent: the use of $t$-BuLi led to an ortho-lithiation functionalisation, taking advantage of the directing ability of the amide group, whereas the employment of less sterically encumbered (or less basic) organolithium reagents (e.g., MeLi, PhLi, n-BuLi, n-HexylLi) prompted $\mathrm{S}_{\mathrm{N} A c}$ pathways. ${ }^{[15 \mathrm{~b}]}$ Ketones, however, always formed 
in combination with the corresponding tertiary alcohols in up to 7:1 ratio (Figure 1e).

Building upon these findings, we herein first report a systematic investigation showing the potential benefits of using an environmentally friendly and recyclable solvent like CPME in the nucleophilic addition of organolithium reagents to cheap and commercially available amides. Under optimised conditions, a variety of structurally diversified ketones were isolated as the sole reaction products, with a broad substrate scope and in short reaction times (20 s) (i) working in batch conditions, (ii) under air at RT and, most importantly, (iii) starting from unmodified and unactivated precursors (e.g., pyrrolidine carboxamide derivatives), and in the absence of any transition metal catalyst (Figure 1f). A spectroscopic investigation, supported by density functional theory (DFT) calculations, provides insights into the stability of the tetrahedral intermediate involved in the reaction mechanism, thereby revealing that it is mainly retained in CPME solution.

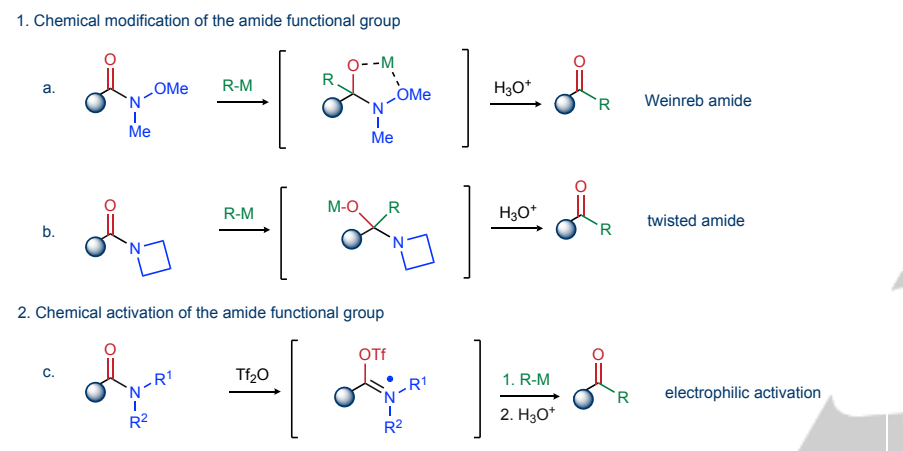

3. Transition metal-catalysed C-N activation reactions

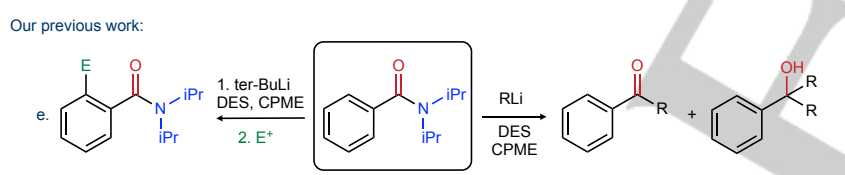

This work:

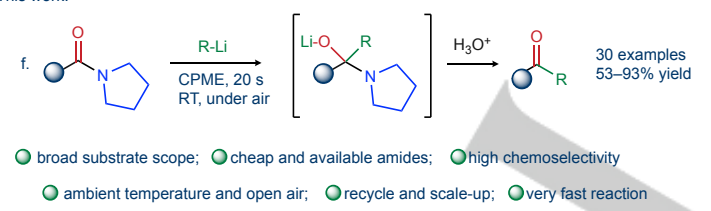

Figure 1. Synthetic strategies available to convert amides into ketones. a. Weinreb amides. b. Acyl azetidines. c. Electrophilic activation of amides. d. Metal catalysed C-N bond activation. e. DoM of benzamides in DES. f. This work: synthesis of ketones starting from unmodified amides under mild conditions. RT = room temperature.

\section{Results and Discussion}

Reaction development. We began our study by investigating the reactivity of a simple amide like $\mathrm{N}$-benzoylpyrrolidine (1a) towards $n$-BuLi under various reaction conditions (Table 1). First, a $0.5 \mathrm{M}$ solution of 1a was reacted with $n$-BuLi (2 equiv) in different solvents under air, and the reaction mixture was quenched with water after $20 \mathrm{~s}$ reaction time.
Table 1. Nucleophilic acyl substitution reaction promoted by $n$-BuLi on $N$ benzoylpyrrolidine (1a) under various conditions. ${ }^{[a]}$

\begin{tabular}{|c|c|c|c|c|}
\hline $1 a$ & $\begin{array}{l}\text { n-BuLi (2 } \\
\text { solvent [C } \\
\text { RT, } 20 \mathrm{~s} \\
\text { open air }\end{array}$ & & & $\overbrace{n-B u}^{\mathrm{OH}}$ \\
\hline Entry ${ }^{[a]}$ & Solvent & Conv. $(\%)^{[b]}$ & $\begin{array}{l}2 a: 3 a \\
\text { ratio }^{[b]}\end{array}$ & $2 a$ yield $(\%)^{[c]}$ \\
\hline 1 & hexane & 88 & $82: 18$ & 71 \\
\hline 2 & DEE & 100 & $92: 8$ & 88 \\
\hline 3 & DME & 100 & $95: 5$ & 89 \\
\hline 4 & TBME & 100 & $95: 5$ & 90 \\
\hline 5 & 2-MeTHF & 100 & $96: 4$ & 89 \\
\hline 6 & 1,4-Dioxane & 100 & $95: 5$ & 88 \\
\hline 7 & Glycerol & 5 & - & - \\
\hline 8 & $\mathrm{H}_{2} \mathrm{O}$ & 13 & $50: 50$ & 4 \\
\hline 9 & CPME & 100 & $97: 3$ & 93 \\
\hline
\end{tabular}

[a] Reaction conditions: substrate 1a $(0.2 \mathrm{mmol})$, solvent $(0.40 \mathrm{~mL}, \mathrm{DEE}=$ diethyl ether, DME = 1,2-dimethoxyethane, TBME = tert-butyl methyl ether), $n$ BuLi (2 equiv, $2.5 \mathrm{M}$ in hexanes), $20 \mathrm{~s}$, under air. [b] Determined by ${ }^{1} \mathrm{H}$ NMR analysis on the crude reaction mixture. [c] Determined by ${ }^{1} \mathrm{H}$ NMR using $\mathrm{CH}_{3} \mathrm{NO}_{2}$ as the internal standard.

The picture emerging from the results compiled in Table 1 can be summarised as follows. The reaction proceeds fast, in satisfactory yields (88-90\%) and with good chemoselectivity in a variety of ethereal solvents with a ketone (2a)-to-alcohol (3a) ratio of up to 96:4 (Table 1, entries 2-6). Conversely, non-coordinating solvents like hexane (Table 1, entry 1 ) provided $\mathbf{2 a}$ in moderate yield only $(71 \%)$, whereas the $S_{N} A c$ was ineffective in protic solvents like glycerol and water (Table 2, entries 7,8). Pleasingly, when 1a was treated $n$-BuLi (2 equiv) in CPME $(0.5 \mathrm{M})$, under air at RT, we observed full conversion of the starting material into valerophenone $\mathbf{2 a}$, which was isolated in $93 \%$ yield after $20 \mathrm{~s}$ reaction time, the $\mathbf{2 a}: 3 \mathbf{a}$ ratio being $97: 3$ (Table 1 , entry 9 ). This last result is particularly satisfying not only in terms of yield and negligible over-addition reaction, but also because CPME is a well recognised eco-friendly solvent and represents a sustainable alternative to the most common ethereal solvents because of its valuable properties such as a relatively high boiling point, low toxicity, non-inflammability, low peroxide formation rate and stability under basic and acidic conditions. ${ }^{[17-18]}$

The next investigation was aimed at the study the effect of (i) the amount of $n$-BuLi, (ii) the reaction time, and (iii) the hexane/CPME ratio on both the conversion of $1 \mathrm{a}$ and the yield of 2a (Figure 2). As shown in Figure 2 (top), reaction times longer than $20 \mathrm{~s}$, as well as a lower amount of $n$-BuLi than 2 equiv, led to a significant decrease of the yield of $2 \mathbf{a}$ (see Supplementary Information for details). At the same time, a 0.2-1.0 M concentration range of $\mathbf{1 a}$ in CPME turned out to be optimal as $\mathbf{2 a}$ was isolated in $91-94 \%$ yield after $20 \mathrm{~s}$ when using 2 equiv $n$-BuLi (Figure 2, bottom). By lowering the CPME:hexane molar fraction, the yield of 2a gradually decreased up to $71 \%$ (pure hexane). A freshly prepared solution of $n$-BuLi in CPME $(1.9 \mathrm{M})^{[19]}$ gave comparable results in terms of yield and conversion. 

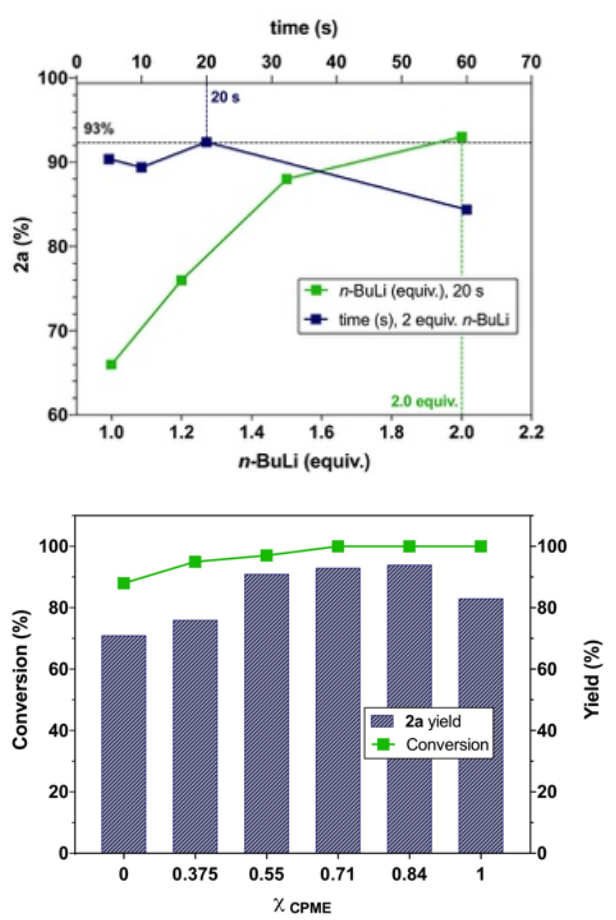

Figure 2. Effect of $n$-BuLi equiv and reaction time on the yield of $\mathbf{2 a}$ (top). Impact of the hexane:CPME ratio on conversion (green line) and yield (bars) of $\mathbf{2 a}$ after 20 s reaction time and using 2 equiv $n$-BuLi (bottom). $\chi$ CPME: 0 (pure hexane), 0.375 (2.0 M in CPME), 0.55 (1.0 M in CPME), 0.71 (0.5 M in CPME), 0.84 (0.2 $\mathrm{M}$ in CPME), 1.0 ( $n$-BuLi in pure CPME).

This testifies that the use of commercial solutions of $n$-BuLi in hexanes $(2.5 \mathrm{M})$ is both feasible and fruitful.

Cognizant of the above achievements, we next investigated the effectiveness of the $S_{N A C}$ reaction on different aromatic carboxylic acid amides 1 (0.5 M in CPME) by varying the nature of the amide leaving group (Scheme 1). After $20 \mathrm{~s}$ reaction time, similarly to $\mathbf{1 a}$, the simplest $N, N$-dimethylbenzamide (1b) delivered ketone $2 a$ in a remarkable $90 \%$ yield and with an excellent 2a-to-3a ratio (97:3) when treated with $n$-BuLi (2 equiv) at RT and under air. An increase of the steric hindrance of the alkyl chains around the nitrogen atom of the amide (1c-e) reduced both the production of $2 \mathbf{a}$ (up to $64 \%$ ) and the $2 \mathrm{a}: 3 \mathbf{a}$ ratio (up to 69:31). Lower yields (67-85\%) were detected when using $\mathrm{N}$-allylated benzamide $\mathbf{1 f}$ or $\mathrm{N}$-benzoylpiperidine $\mathbf{1 g}$ as the substrate, though still with an excellent ketone-to-alcohol ratio (93:7). Remarkably, the reaction of $n$-BuLi with a CPME solution of $\mathrm{N}$-benzoylazetidine $1 \mathrm{~h}$, which is characterised by a significant pyramidalization around the nitrogen atom, at RT and under air, gave almost similar results (2a: 90\% yield; 2a:3a ratio: 94:6) compared to the ones obtained with simpler and cheaper amides like $\mathbf{1 a}$ and $\mathbf{1 b}$. Conversely, the described protocol does not apply well to derivatives like $\mathrm{N}$-benzoylpyrrole $1 \mathrm{i}$. Indeed, the peculiar reactivity of these compounds relies on the exceptional stability of the corresponding tetrahedral intermediates upon addition of an organometallic reagent, leading to pyrrolyl carbinols under kinetic conditions. ${ }^{[20]}$ The latter act as masked carbonyl equivalents whose carbonyl functionality is revealed under thermodynamic basic conditions. In addition, the corresponding O-lithiated pyrrolyl carbinols are known to undergo a fast decomposition at temperatures higher than $-30{ }^{\circ} \mathrm{C}$. It is thus with no surprise that the reaction of $1 \mathbf{i}$ with $n$-BuLi quickly provided the bis(alkylated) alcohol $3 \mathbf{a}$ in $75 \%$ yield as the sole product. Finally, we found that the treatment of a CPME solution of the Weinreb amide $1 \mathrm{j}$ with $n$ BuLi gave comparable results to those specified in the case of amides $\mathbf{1 a}$ and $\mathbf{1 b}$ as ketone $\mathbf{2 a}$ was isolated in $91 \%$ yield and with a $2 \mathbf{a}: 3 \mathbf{a}$ ratio of $98: 2$. All in all, these results disclose that $(i)$ amides $1 \mathrm{a}, \mathbf{1 b}$ and $\mathbf{1 j}$ stand on the same ground with reference to their reactivity towards organolithium reagents, and (ii) even in the absence of a strong internal chelation of the lithium cation $(\mathbf{1 j})$ or of an amide bond twisting (1h) the collapse of the tetrahedral intermediate ${ }^{[21]}$ can equally be strongly disfavored by simply using CPME as the solvent, at room temperature and under air, and commercial solution of $\mathrm{RLi}$ reagents, with the $\mathrm{S}_{N} A c$ reactions taking place very fast $(20 \mathrm{~s})$ and in high yields.
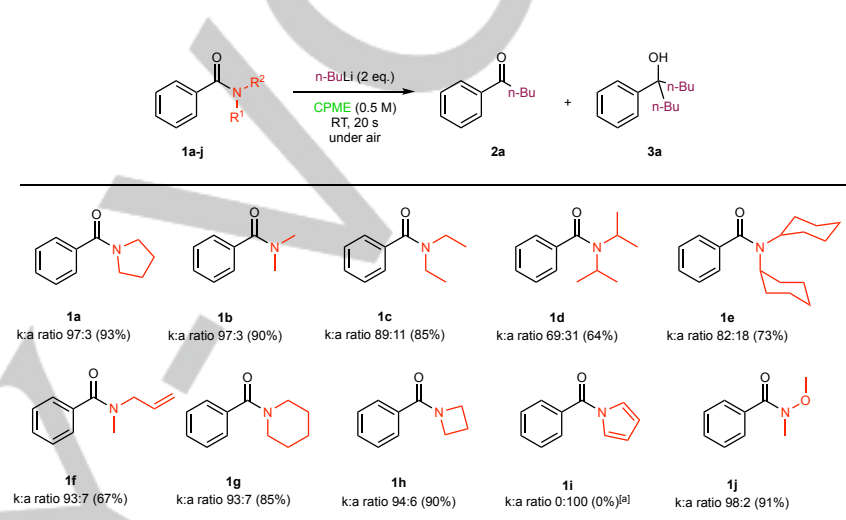

Scheme 1. Nucleophilic acyl substitution reaction on different benzamides 1a1j using $n$-BuLi in CPME at RT under air. Reaction conditions: $1(0.2 \mathrm{mmol})$, CPME $(0.4 \mathrm{~mL}), n$-BuLi $(2.5 \mathrm{M}$ in hexanes, $0.4 \mathrm{mmol})$, quench with water after $20 \mathrm{~s}$. Ketone $(k)$-to-alcohol $(a)$ ratio values were determined by ${ }^{1} \mathrm{H}$ NMR integration on the crude reaction mixture. Yields in round brackets refer to valerophenone $2 \mathrm{a}$ determined by ${ }^{1} \mathrm{H}$ NMR analysis using $\mathrm{CH}_{3} \mathrm{NO}_{2}$ as the internal standard. [a] Yield of 3a: $75 \%$.

Mechanistic investigations. ${ }^{1} \mathrm{H}-\mathrm{NMR}$ analysis was performed to investigate the formation and the stability of the tetrahedral intermediate under our reaction conditions. After the addition of $n$ BuLi (2.0 M in cyclohexane, 1.1 equiv) to a $0.5 \mathrm{M}$ solution of $1 \mathrm{a}$ ( $0.35 \mathrm{mmol}, 1.0$ equiv) in dry CPME under nitrogen, neither lithium pyrrolidin-1-ide nor starting material (1a) or valerophenone (2a) were detected in the ${ }^{1} \mathrm{H}$ NMR spectra (Figure 3). Evidence of the formation of the tetrahedral intermediate tetr-1a was assessed by a significant change of the aromatic pattern alongside with a remarkable upfield shift of the $N-\alpha$ methylenic protons of the pyrrolidine unit. Partial collapse of the tetrahedral intermediate into valerophenone $2 \mathrm{a}$ was observed by ${ }^{1} \mathrm{H}$ NMR after several days of experiment (six days), while open-air conditions induced the instantaneous conversion of tetr-1a into the corresponding ketone (see Supplementary Information for details).

To gain more insights into such a somewhat unexpected remarkable stability of the tetrahedral intermediate under the aforementioned conditions and to support the observed ${ }^{1} \mathrm{H}$ NMR analysis (Figure 3 ), we investigated its geometry and calculated the Free Energy barriers of the $S_{N A c}$ reaction by DFT computations. DFT calculations were run at the M06-2X/aug-ccpVTZ//M06-2X/6-311+G(d) level for amides $\mathbf{1 a}, \mathbf{1 b}$, and $\mathbf{1 j}$. 


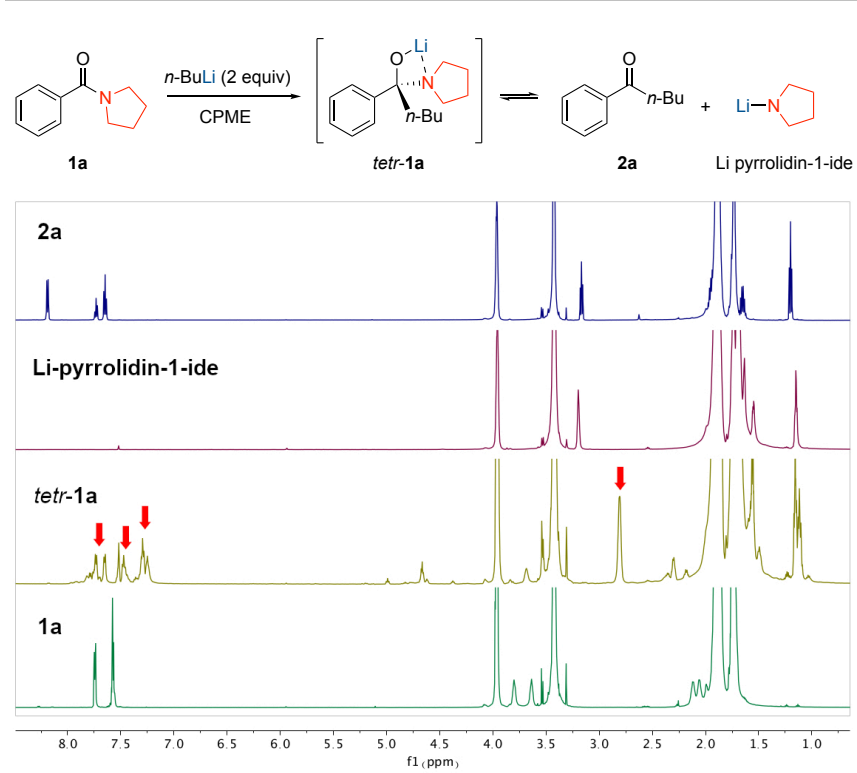

Figure 3. ${ }^{1} \mathrm{H}$ NMR evidence of tetr-1a formation. Experiments were recorded in dry CPME using $\mathrm{CDCl}_{3}$ as an internal reference. Red arrows indicate the signals of tetr-1a.

The mechanism involves (i) pre-complexation of the starting amide by O-Li coordination (TS1, Figure 4), (ii) evolution of TS1 to the corresponding monomeric tetrahedral intermediate (tetr-1, Figure 4), and (iii) the collapse of tetr-1 into ketone $2 \mathrm{a}$ through a second transition state (TS2, Figure 4). Computational results revealed that the addition of the organolithium reagent is a fast reaction (TS1, Free Energy barriers: $9-15 \mathrm{kcal} \mathrm{mol}^{-1}$ ) producing rather stable monomeric tetrahedral intermediates (tetr-1a, tetr1b, tetr-1j, Figure 4) with respect to the starting reactants. The cleavage barrier of the $\mathrm{C}-\mathrm{N}$ bond determines the kinetic stabilities of the intermediates. By considering the ZPE energy correction, our results are in fairly good agreement with the previous findings reported by Boche and co-workers, ${ }^{[6 b]}$ where the reactivity of "classical" and Weinreb amides towards $S_{N} A c$ was studied by DFT calculations using formamide and $\mathrm{N}$-hydroxyformamide as model substrates, respectively. However, the Free Energy barriers of the second step are in contrast with the experimental stability of the tetrahedral intermediates. As an example, when the nucleophilic acyl substitution reaction of $1 \mathbf{a}$ in dry CPME with $n$ BuLi is performed under anhydrous conditions, aqueous quench after $24 \mathrm{~h}$ affords the corresponding ketone 2a with negligible formation of over-addition products (see Supplementary Information for details). By contrast, the Free Energy barriers of about $21 \mathrm{kcal} \mathrm{mol}^{-1}$ correspond to half-life times of the order of hundreds of seconds. Quantitative agreement with the experiments is obtained only considering the formation of putative dimeric aggregates in solution and including two explicit molecules of CPME in the computations. ${ }^{[22]}$ In this case, the Free Energy barriers of the second step raise to more than $40 \mathrm{kcal} \mathrm{mol}^{-}$ ${ }^{1}$ for both $\mathbf{1 a}$ and $\mathbf{1 b}$ (Figure 4). When CPME was replaced by the non-coordinating solvent hexane, the Free Energy Barriers of the dimeric form for the second step dropped down to $19 \mathrm{kcal} \mathrm{mol}^{-1}$, which suggest low selectivity in hydrocarbons, in agreement with the experimental results (Table 1 , entry 1 , see Supplementary Information for details).

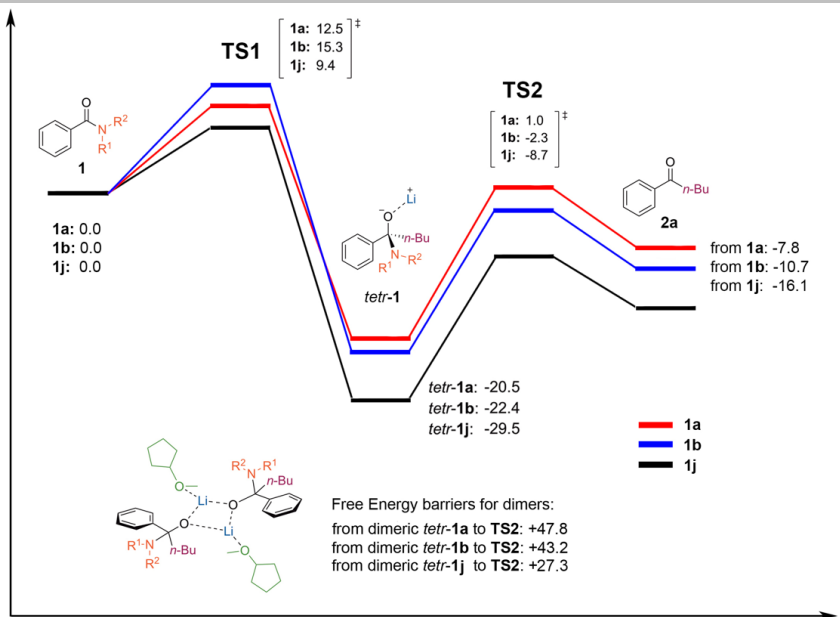

Figure 4. Reaction mechanism and calculated Free Energy barriers (kcal mol1) for products formation starting from monomeric or coordinated dimeric structures tetr-1a, tetr-1b, and tetr-1j. 1a: $\mathrm{R}^{1}=\mathrm{R}^{2}=-\left(\mathrm{CH}_{2}\right)_{4}-; \mathbf{1} \mathbf{b}: \mathrm{R}^{1}=\mathrm{R}^{2}=\mathrm{Me}$; 1j: $R^{1}=M e, R^{2}=$ OMe

\section{(n)}

The decomposition rate of the tetrahedral intermediate in the presence of water was finally evaluated by DFT computations. Calculations were run on tetr-1b at the same theory level. Assuming that a fast acid-base equilibrium en route to an hydroxyamino derivative takes place, the Free Energy barrier for the amide decomposition into ketone $2 \mathbf{a}$ and dimethylamine was quantitatively evaluated as $10.1 \mathrm{kcal} \mathrm{mol}^{-1}$ by adding one explicit molecule of water to PCM calculations. This was necessary to create the cooperative effect which promotes the $\mathrm{C}-\mathrm{N}$ bond dissociation that needs to be taken into account to avoid an overestimation of the Free Energy barrier of about $15 \mathrm{kcal} \mathrm{mol}^{-1}$.

Scope of the reaction. With satisfactory conditions in place, we sought to capitalize on this process by exploring the scope of this transformation. By reacting a variety of aliphatic and (hetero)aromatic $N$-acyl pyrrolidines $1 \mathbf{a}, \mathbf{1 k}-\mathbf{1 x}$ with commercially available aliphatic and (hetero)aromatic organolithium reagents ranging from $n$-BuLi to $s$-BuLi, $t$-BuLi, $n$-HexylLi, PhLi and 2thienylLi (Scheme 2), a wide range of ketones $\mathbf{2 b - 2 a d}$ were synthesized in very satisfactory yields (53-93\%). Unsubstituted $\mathbf{2 b - 2 f}$, as well as ketones decorated with electron-donating (MeO, $\mathbf{2 g}-\mathbf{2 j}$ ), neutral (Me, $\mathbf{2 k - 2 m}$ ) or electron-withdrawing $(\mathrm{Br}, \mathbf{2 n}, \mathbf{0}$; $\mathrm{CF}_{3}, \mathbf{2 q}, \mathbf{r}$ ) substituents, were smoothly obtained with different ring substitution patterns [ortho- $(\mathbf{2} \mathbf{g}, \mathbf{h}, \mathbf{2 m})$, meta- $(\mathbf{2} \mathbf{i}, \mathbf{j})$ and para$(\mathbf{2 k}, \mathbf{l}, \mathbf{2 n}, \mathbf{0}, \mathbf{2 q}, \mathbf{r})]$ in $60-88 \%$ yields. Of note, all the aforementioned transformations proved to be highly chemoselective, and do not suffer competitive pathways such as DoM $(\mathbf{2} \mathbf{g}-\mathbf{2 j})$, lateral lithiation $(\mathbf{2 k}-\mathbf{2 m})$ or lithium-halogen exchange $(2 \mathbf{2 n}, \mathbf{0})$ reactions. Assorted (hetero)aryl derivatives with a fluorine substituent (2p), electron-deficient (pyridine: $2 \mathbf{s}, \mathbf{t}$ ), and electron-rich (thiophene: $\mathbf{2 u}, \mathbf{v}, \quad N$-methylindole: $\mathbf{2} \mathbf{w}, \mathbf{x}$ ) heterocycles served as competent reaction partners as well, thereby delivering the desired ketones in 53-93\% yield. It is worth noting that, under the above conditions, even (cyclo)alkyl (2y2ab), bicyclic (2ac) and sterically hindered adamantyl (2ad) ketones could be obtained from the corresponding acyl pyrrolidines in $55-89 \%$ yield. These results thus testify to the generality of the described protocol for the ketone synthesis from amides. ${ }^{[23]}$ 


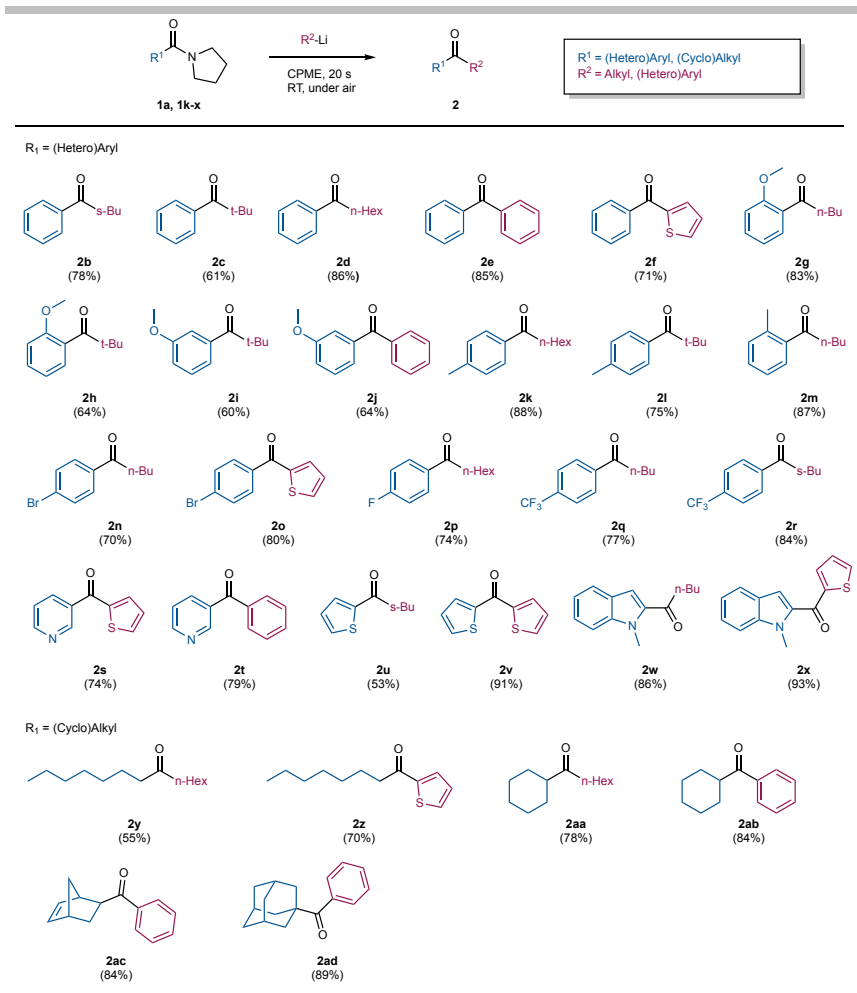

Scheme 2. Synthesis of ketones 2 through the nucleophilic acyl substitution reaction between aliphatic and (hetero)aromatic $N$-acylpyrrolidines 1 and aliphatic and (hetero)aromatic organolithium reagents in CPME, at RT and under air. Reaction conditions: $1(0.2 \mathrm{mmol}), \mathrm{R}^{2} \mathrm{Li}(0.4 \mathrm{mmol}), \mathrm{CPME}(0.4 \mathrm{~mL})$, $20 \mathrm{~s}$. Yields refer to products isolated after flash-column chromatography. $1 \mathbf{k}$ $\mathrm{N}$-2-methoxybenzoyl pyrrolidine; 1I: N-3-methoxybenzoyl pyrrolidine; 1m: N-4methylbenzoyl pyrrolidine; 1n: N-2-methylbenzoyl pyrrolidine; 10: $\mathrm{N}-4$ bromobenzoyl pyrrolidine; 1p: N-4-fluorobenzoyl pyrrolidine; 1q: $N-4$ trifluoromethylbenzoyl pyrrolidine; $1 \mathrm{r}$ : $\mathrm{N}$-nicotinoyl pyrrolidine; $1 \mathrm{~s}$ : $\mathrm{N}$-thiophene2-carbonyl pyrrolidine; 1t: $\mathrm{N}$-1-methyl-1H-indole-2-carbonyl pyrrolidine; $1 \mathrm{u}: \mathrm{N}$ octanoyl pyrrolidine; 1v: $\mathrm{N}$-cyclohexanecarbonyl pyrrolidine; $\mathbf{1 w}$ : $\mathrm{N}$ norbornenecarbonyl pyrrolidine; 1x: $\mathrm{N}$-adamantanoyl pyrrolidine.

Scalability and recycle. To further explore the utility, the versatility and the robustness of this new sustainable synthetic protocol and to improve its atom economy, we investigated the scalability of the process. To this end, we carried out a gram scale synthesis of $\mathbf{2} \mathbf{d}$ starting from $\mathbf{1 a}$. By reacting a solution of $\mathbf{1 a}(11.4$ mmol, $2 \mathrm{~g}$, in $22 \mathrm{~mL} \mathrm{CPME)} \mathrm{with} n$-HexylLi (2 equiv, $2.3 \mathrm{M}$ in hexanes), the reaction proceeded uneventfully in $20 \mathrm{~s}$ at RT under air, and resulted in the formation of $\mathbf{2 d}$ in $90 \%$ yield $(2 \mathrm{~g})$ and with a 97:3 ketone-to-alcohol ratio. Furthermore, in order to prepare additional starting material, we also investigated the recyclability and the reusability of both the solvent (CPME) and the pyrrolidine leaving group (b.p. $=87^{\circ} \mathrm{C}$ ) by distillation (Scheme 3 ). To this end, a solution of $1 \mathrm{a}(5.7 \mathrm{mmol}, 1 \mathrm{~g}$, in $11 \mathrm{~mL}$ CPME) was reacted with $n$-HexylLi (2 equiv, $2.3 \mathrm{M}$ in hexanes). The resulting crude reaction mixture was carefully fractionally distilled. This favored an easy recovery of the CPME/hexane fraction containing the pyrrolidine. The latter was finally successfully acylated with benzoyl chloride, thereby affording the starting material $1 \mathrm{a}$ in $74 \%$ isolated yield and allowing, at the same time, the recovery of ketone $2 \mathrm{~d}$ in $86 \%$ yield $(1 \mathrm{~g})$ after purification.

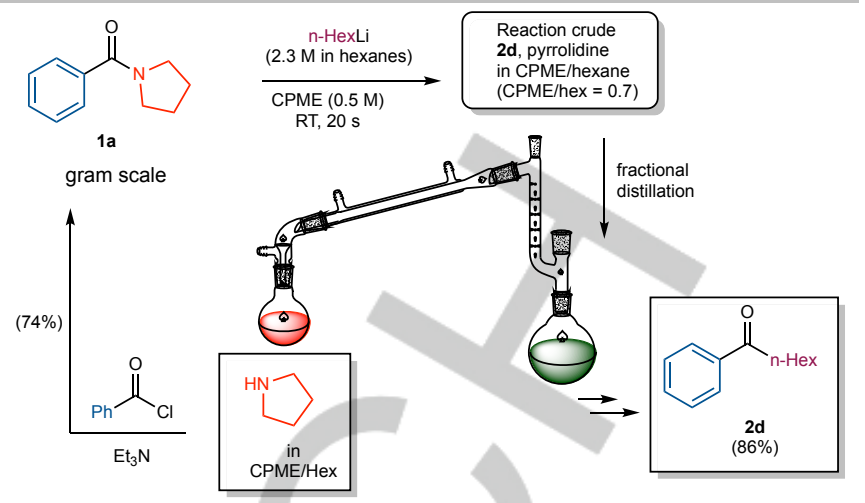

Scheme 3. Gram-scale synthesis of $\mathbf{2} \mathbf{d}$ and recycling procedure of CPME and pyrrolidine from the acylation reaction. Reaction conditions: $1 \mathrm{a}(1 \mathrm{~g}, 5.7 \mathrm{mmol})$, $n$-HexLi $(4.96 \mathrm{~mL}, 11.4 \mathrm{mmol})$, CPME $(11 \mathrm{~mL}), 20 \mathrm{~s}$. Yields refer to products isolated after flash-column chromatography.

\section{Conclusions}

In summary, this work discloses that there is no need to make use of chemically modified or activated amides as well as transition metal-catalysed $\mathrm{C}-\mathrm{N}$ activation processes to promote and privilege nucleophilic acyl substitution reactions by organolithium reagents. Indeed, both aliphatic and (hetero)aromatic $\mathrm{N}$-acylpyrrolidines have been found to successfully react with commercial solution of aliphatic and (hetero)aromatic organolithiums, with the desired ketones obtained in up to $93 \%$ yield (30 cases investigated and discussed) and with an effective suppression of the notorious over-addition reaction, when using CPME $(0.5 \mathrm{M}$ solution $)$ as an environmentally responsible solvent. Valuable points of practical interest of the presented protocol are (i) reactions run in open air and at room temperature with extremely fast reaction times $(20 \mathrm{~s})$, (ii) tolerance of several electron-donating, electron-deficient and sterically hindered functional groups, and (iii) high chemoselectivity with no competition with potential DoM, lateral and halogen-exchange pathways.

The utility and the sustainability of the process was further highlighted by its scalability and the recyclability/reusability of both the solvent and the pyrrolidine leaving group to prepare additional starting material. The experimental results are nicely supported by detailed DFT calculations that show how CPME stabilizes the dimeric tetrahedral intermediate, and by NMR spectroscopic investigations, which provide insights into the stability of the tetrahedral intermediate in CPME solution.

\section{Experimental Section}

Experimental Details

Preparation of 2-thienyllithium solution in CPME. In a Schlenk tube under a positive pressure of nitrogen, $t$-BuLi $(1.7 \mathrm{M}$ in pentane, $2.0 \mathrm{mmol}$, 2.0 equiv) was added dropwise to a precooled $\left(-78^{\circ} \mathrm{C}\right)$ stirred solution of 2-bromothiophene (1.0 mmol, 1.0 equiv, $97 \mu \mathrm{L})$ in dry CPME (1 mL, $1 \mathrm{M}$ ). The reaction was stirred at $-78^{\circ} \mathrm{C}$ for $1 \mathrm{~h}$ to yield a pale-yellow solution of 2-thienyllithium (2-ThLi). The exact concentration was determined by titration with diphenylacetic acid prior to use. 
Preparation of $\boldsymbol{n}$-butyllithium solution in CPME. A solution of $n$-BuLi (2.5 $\mathrm{M}$ in hexanes, $5 \mathrm{~mL}$ ) in dry CPME $(5 \mathrm{~mL})$ was added to a test tube fitted with a septum and flushed with dry argon. The tube was then placed under vacuum $(45 \mathrm{mmHg})$ until $5 \mathrm{~mL}$ of concentrated solution was obtained. The resulting solution was diluted again with freshly distilled CPME $(5 \mathrm{~mL})$ and concentrated under vacuum up to a $5 \mathrm{~mL}$ residual volume. This procedure was repeated three times to completely remove residual traces of hexane. The final $n$-BuLi solution in CPME was titrated with diphenylacetic acid in anhydrous THF prior to use.

General procedure for $S_{N} A c$ and synthesis of compounds $2 b-2 a d$. Reactions were performed under air at room temperature. In an open screw cap vial, $N$-acylpyrrolidines $1 \mathbf{a}, \mathbf{1 k}-\mathbf{1 x}(0.2 \mathrm{mmol}, 1$ equiv) were dissolved in CPME (0.4 mL, 0.5 M). The selected organolithium reagent ( $n$-BuLi $2.5 \mathrm{M}$ in hexanes, s-BuLi 1.4 M in cyclohexane, $t$-BuLi 1.7 $\mathrm{M}$ in pentane, $n$-HexLi $2.3 \mathrm{M}$ in hexanes, PhLi $1.9 \mathrm{M}$ in di- $n$-butyl ether, freshly prepared 2-ThLi, $0.4 \mathrm{mmol}, 2.0$ equiv) was rapidly spread over the mixture, which was kept under vigorous stirring for $20 \mathrm{~s}$ (60 s for PhLi and 2-ThLi), and then diluted with water. The mixture was washed twice with $1 \mathrm{M} \mathrm{HCl}$ $(5 \mathrm{~mL})$ and extracted with $\mathrm{Et}_{2} \mathrm{O}(3 \times 5 \mathrm{~mL})$. The combined organic layers were dried over $\mathrm{Na}_{2} \mathrm{SO}_{4}$ and the solvent removed under reduced pressure. The crude products were purified by flash column chromatography on silica gel.

Experimental procedure for the recycle of CPME and pyrrolidine through the acylation reaction. In a $100 \mathrm{~mL}$ round-bottom flask, phenyl(pyrrolidin-1-yl)methanone 1a $(5.7 \mathrm{mmol}, 1.0$ equiv, $1.0 \mathrm{~g})$ was dissolved in CPME (11.4 mL, 0.5 M) under air. $n$-HexLi (2.3 M in hexanes, $11.4 \mathrm{mmol}, 2.0$ equiv) was rapidly spread over the mixture at room temperature, which was kept under vigorous stirring and quenched after $20 \mathrm{~s}$ with a stoichiometric amount of water (11.4 mmol, 2.0 equiv, $205 \mu \mathrm{L}$ ). The crude reaction mixture was transferred to a Claisen distillation apparatus fitted with a $20 \mathrm{~cm}$ Vigreux column. Fractional distillation at 760 $\mathrm{mmHg}$ afforded a mixed fraction containing all the volatiles components of the reaction crude (hexane, pyrrolidine and CPME). The residual nonvolatile fraction recovered from the distillation apparatus, containing mostly ketone 2d and inorganic salts, was directly purified by flash column chromatography (petroleum ether/Et $2 \mathrm{O} 95 / 5 \mathrm{v} / \mathrm{v} \%$ ) to give pure 1 phenylheptan-1-one 2d (931 mg, 86\%). The pyrrolidine solution in $\mathrm{CPME} /$ hexane was recycled as a substrate for the preparation of benzamide 1a. Benzoyl chloride ( $6.8 \mathrm{mmol}, 1.2$ equiv, $790 \mu \mathrm{L}$ ) and $\mathrm{Et}_{3} \mathrm{~N}$ (11.4 mmol, 2.0 equiv, $1.58 \mathrm{~mL}$ ) were quickly sequentially added to the pyrrolidine solution in $\mathrm{CPME} /$ hexane at $0{ }^{\circ} \mathrm{C}$, and the mixture was stirred overnight at RT. The mixture was washed with $1 \mathrm{M} \mathrm{HCl}(2 \times 20 \mathrm{~mL})$ and saturated aq. $\mathrm{NaHCO}_{3}(20 \mathrm{~mL})$, followed by extraction with $\mathrm{CPME}(3 \times 20$ $\mathrm{mL}$ ). The combined organic layers were dried over $\mathrm{Na}_{2} \mathrm{SO}_{4}$ and the solvent was removed under reduced pressure. Purification by flash column chromatography afforded $1 \mathrm{a}$ as a yellow oil $\left(858 \mathrm{mg}, 86 \%, \mathrm{R}_{f}=0.20\right.$ petroleum ether/EtOAc 1/1 v/v).

DFT calculations for amides $1 \mathrm{a}, 1 \mathrm{~b}$ and $1 \mathrm{j}$

Minima and transition structures were determined within the Density Functional Theory (DFT-PCM), ${ }^{[2]}$ and making use of the M06-2X functional.[25] The polarized split-valence shell $6-311+G(d)$ was used for the optimizations. ${ }^{[26]}$ The nature of the critical points was checked by vibrational ana lysis. All the molecules were considered as a solute in a polarized continuum, within the Solvation Model based on Density $(\mathrm{SMD})^{[27]}$ and Integral Equation Formalism-Polarizable Continuum Model (IEF-PCM) schemes. ${ }^{[28]}$ For a better energy assessment, two molecules of explicit solvent (CPME) in interaction with the ionic centers, were added in the computations. The optimisations were followed by aug-cc-pVTZ[29] single-point energy calculations (including PCM), and free energies were estimated by adding the thermochemical contributions obtained at M06$2 X / 6-311+G(d)$ level. These $\Delta G$ (at 298K) values at DFT(M06-2X)/aug-ccpVTZ are reported throughout in the text. A complete set of critical point geometries and energies is reported in the Supporting Information. All calculations were carried out by using the GAUSSIAN16 system of programs. ${ }^{[30]}$

\section{Acknowledgements}

We would like to acknowledge Prof. Vittorio Pace for helpful discussions and suggestions, Dr. Emanuele Priola for technical support. Huvepharma Italia srl, Regione Piemonte and Cassa di Risparmio di Torino for financial support. V.C. thanks the Interuniversity Consortium C.I.N.M.P.I.S. and the University of Bari for supporting this work.

Keywords: ketones $\cdot$ amides $\cdot$ organolithiums $\cdot$ chemoselectivity - carbanions

\section{References}

[1] a) B. M. Trost, Science 1983, 219, 245; b) G. A. Olah, G K. Surya Prakash, M. Arvanaghi, Synthesis 1984, 1984, 228-230; c) G. Zadel, E. Breitmaier, Angew. Chem. Int .Ed. 1992, 31, 1035-1036.

[2] D. Seebach, Angew. Chem. Int .Ed. 2011, 50, 96-101.

[3] a) K. Colas, A. C. V. dos Santos, A. Mendoza, Org. Lett. 2019, 21, 7908-7913; b) A. Nagaki, K. Sasatsuki, S. Ishiuchi, N. Miuchi, M. Takumi, J. i. Yoshida, Chem. Eur. J. 2019, 25, 4946-4950; c) Y.-Q. Guo, R. Wang, H. Song, Y. Liu, Q. Wang, Org. Lett. 2020, 22, 709-713; d) J. Li, R. Oost, B. Maryasin, L. González, N. Maulide, Nature Commun. 2019, 10, 1-7; e) M. J. Jorgenson, in Org. React., 2011, pp. 1-98; f) T. E. Hurst, J. A. Deichert, L. Kapeniak, R. Lee, J. Harris, P. G. Jessop, V. Snieckus, Org. Lett. 2019, 21, 3882-3885.

[4] R. K. Dieter, Tetrahedron 1999, 55, 4177-4236.

[5] D. T. Genna, G. H. Posner, Org. Lett. 2011, 13, 53585361.

[6] a) W. S. Bechara, G. Pelletier, A. B. Charette, Nat. Chem. 2012, 4, 228-234; b) M. Adler, S. Adler, G. Boche, J. Phys. Org. Chem. 2005, 18, 193-209; c) A. R. Katritzky, K. N. B. Le, L. Khelashvili, P. P. Mohapatra, J. Org. Chem. 2006, 71, 9861-9864.

[7] a) V. R. Pattabiraman, J. W. Bode, Nature 2011, 480, 471; b) C. L. Allen, J. M. Williams, Chem. Soc. Rev. 2011, 40, 3405-3415

[8] a) L. Pauling, Cornell Univ 1967, 64; b) P. Sureshbabu, S. Azeez, N. Muniyappan, S. Sabiah, J. Kandasamy, J. Org. Chem 2019, 84, 11823-11838; c) M. M. Mehta, T. B. Boit, J. E. Dander, N. K. Garg, Org. Lett. 2019, 22, 1-5; d) C.-G. Yu, Y. Matsuo, Org. Lett. 2020, 22, 950-955.

[9] a) R. Senatore, L. lelo, S. Monticelli, L. Castoldi, V. Pace, Synthesis 2019, 51, 2792-2808; b) W. Sun, L. Wang, Y. $\mathrm{Hu}$, X. Wu, C. Xia, C. Liu, Nature Commun. 2020, 11, 3113; c) C. Liu, M. Achtenhagen, M. Szostak, Org. Lett. 2016, 18, 2375-2378.

[10] a) T. Sato, N. Chida, Org. Biomol. Chem. 2014, 12, 31473150; b) L. Castoldi, W. Holzer, T. Langer, V. Pace, Chem. Commun. 2017, 53, 9498-9501.

[11] G. Li, M. Szostak, Chem. Eur. J. 2020, 26, 611-615.

[12] a) H. Geng, P. Q. Huang, Chin. J. Chem . 2019, 37, 811816; b) P.-Q. Huang, Y. Wang, K.-J. Xiao, Y.-H. Huang, Tetrahedron 2015, 71, 4248-4254. 
[13] a) G. Meng, R. Szostak, M. Szostak, Org. Lett. 2017, 19 3596-3599; b) P.-Q. Huang, H. Chen, Chem. Commun. 2017, 53, 12584-12587.

[14] J. de Jong, D. Heijnen, H. Helbert, B. L. Feringa, Chem. Commun. 2019, 55, 2908-2911.

[15] a) D. Arnodo, S. Ghinato, S. Nejrotti, M. Blangetti, C. Prandi, Chem. Commun. 2020, 56, 2391-2394; b) S. Ghinato, G. Dilauro, F. M. Perna, V. Capriati, M. Blangetti, C. Prandi, Chem. Commun. 2019, 55, 7741-7744.

[16] a) F. M. Perna, P. Vitale, V. Capriati, Current Opinion in Green and Sustainable Chemistry 2020, 21, 27-33; b) E. L. Smith, A. P. Abbott, K. S. Ryder, Chem.Rev. 2014, 114, 11060-11082; c) D. J. Ramón, G. Guillena, Deep Eutectic Solvents: Synthesis, Properties, and Applications, John Wiley \& Sons, 2020.

[17] U. Azzena, M. Carraro, L. Pisano, S. Monticelli, R. Bartolotta, V. Pace, ChemSusChem 2019, 12, 40-70.

[18] G. de Gonzalo, A. R. Alcántara, P. Domínguez de María, ChemSusChem 2019, 12, 2083-2097.

[19] A. Corruble, D. Davoust, S. Desjardins, C. Fressigné, C. Giessner-Prettre, A. Harrison-Marchand, H. Houte, M.-C. Lasne, J. Maddaluno, H. Oulyadi, J. Am. Chem. Soc. 2002, 124, 15267-15279.

[20] D. A. Evans, G. Borg, K. A. Scheidt, Angew. Chem. Int .Ed. 2002, 41, 3188-3191.

[21] a) M. Adler, M. Marsch, N. S. Nudelman, G. Boche Angew. Chem. Int .Ed. 1999, 38, 1261-1263; b) D. L. Comins, Synlett 1992, 1992, 615-625.

[22] Dimeric aggregates have already been observed for dimethyl benzamide when reacted with PhLi. In the dimeric structure the two lithium atoms are bound to the anionic $\mathrm{O}$ atoms and to a single THF molecule, leading to three-coordinate Li cations. See ref $21 \mathrm{a}$.

[23] Esters and nitro groups as subsituents are not compatible with the reaction conditions.

[24] J. L. Calais, 1989, 47, 101-101.

[25] Y. Zhao, D. G. Truhlar, Theor. Chem. Acc. 2008, 120, 215-241.

[26] a) A. McLean, G. Chandler, J. Chem. Phys. 1980, 72, 5639-5648; b) R. Krishnan, J. S. Binkley, R. Seeger, J. A. Pople, J. Chem. Phys. 1980, 72, 650-654; c) T. Clark, J. Chandrasekhar, G. W. Spitznagel, P. V. R. Schleyer, J. Comput. Chem. 1983, 4, 294-301.

[27] A. V. Marenich, C. J. Cramer, D. G. Truhlar, J. Phys. Chem. B 2009, 113, 6378-6396.

[28] J. Tomasi, B. Mennucci, E. Cances, J. Mol. Strut. THEOCHEM 1999, 464, 211-226.

[29] R. A. Kendall, T. H. Dunning Jr, R. J. Harrison, J. Chem. Phys. 1992, 96, 6796-6806.

[30] G. W. T. M. J. Frisch, H. B. Schlegel, G. E. Scuseria, M. A Robb, J. R. Cheeseman, G. Scalmani, V. Barone, G. A. Petersson, H. Nakatsuji, X. Li, M. Caricato, A. V. Marenich, J. Bloino, B. G. Janesko, R. Gomperts, B. Mennucci, H. P. Hratchian, J. V. Ortiz, A. F. Izmaylov, J. L. Sonnenberg, D. Williams-Young, F. Ding, F. Lipparini, F. Egidi, J. Goings, B. Peng, A. Petrone, T. Henderson, D. Ranasinghe, V. G. Zakrzewski, J. Gao, N. Rega, G. Zheng, W. Liang, M. Hada, M. Ehara, K. Toyota, R. Fukuda, J. Hasegawa, M. Ishida, T. Nakajima, Y. Honda, O. Kitao, H. Nakai, T. Vreven, K. Throssell, J. A. Montgomery, Jr., J. E. Peralta, F. Ogliaro, M. J. Bearpark, J. J. Heyd, E. N. Brothers, K. N. Kudin, V. N. Staroverov, T. A. Keith, R. Kobayashi, J. Normand, K. Raghavachari, A. P. Rendell, J. C. Burant, S. S. lyengar, J. Tomasi, M. Cossi, J. M. Millam, M. Klene, C. Adamo, R. Cammi, J. W. Ochterski, R. L. Martin, K. Morokuma, O. Farkas, J. B. Foresman, and D. J. Fox, Inc., Wallingford CT 2009, 121, $150-166$. 


\section{Entry for the Table of Contents}

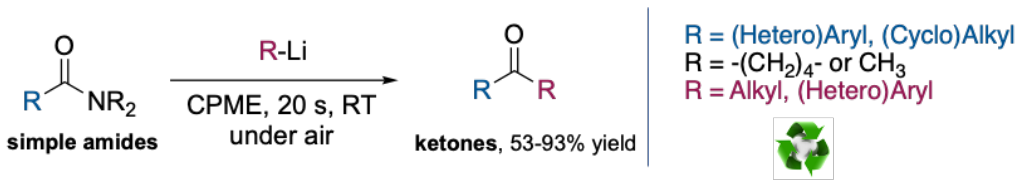

Broad Substrate Scope $\square$ Cheap and Available Amides $\square$ Ambient Temperature and Open Air

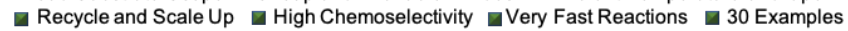

SNAc with organolithiums under air achieved: Aliphatic and (hetero)aromatic ketones are straightforwardly, chemoselectively and quickly (20s reaction time) obtained in up to $93 \%$ yield and with a broad substrate scope by reacting organolithium reagents with a variety of amides at ambient temperature and under air in the environmentally friendly cyclopentyl methyl ether (CPME). Gram scale preparations and recyclability of the reagents have also been successfully accomplished.

Institute and/or researcher Twitter usernames: @Capriati_V @farmuniba @LabPrandi @kristinaprandi 